\title{
Teatro Comparado, territorialidad y espectadores: multiplicidades intraterritoriales
}

\author{
Jorge Dubatti \\ Universidad de Buenos Aires
}

\section{Resumen}

El Teatro Comparado y los conceptos de territorialidad, interterritorialidad, intraterritorialidad y supraterritorialidad habilitan un nuevo diseño de la cartografía teatral, exigida hoy por la indispensable actualización de la Teatrología. La territorialidad considera el teatro en contextos geográficohistórico-culturales de relación y diferencia cuando se los contrasta con otros contextos. Se distinguen dos tipos fundamentales de territorialidad teatral: la territorialidad geográfica y la corporal. La territorialidad comparatista es concebida como espacio subjetivado, espacio construido a partir de procesos de territorialización (procesos de subjetivación), desterritorialización y la reterritorialización. Como ejemplo de complejidad intraterritorial se analizan las respuestas de los espectadores de Buenos Aires, en 2013, al concepto de "teatro comercial de arte».

\section{Palabras clave}

Teatro Comparado · Territorialidad Espacio · Subjetividad . Espectadores

\footnotetext{
- Jorge Dubatti es Doctor (Área de Historia y Teoría de las Artes) por la Universidad de Buenos Aires. Premio Academia Argentina de Letras 1989. Profesor Titular Regular de Historia del Teatro Universal, Carrera de Artes, Facultad de Filosofía y Letras, Universidad de Buenos Aires. Director por concurso público del Instituto de Artes del Espectáculo «Dr. Raúl H. Castagnino» en dicha casa de estudios. Fundador y director de la Escuela de Espectadores de Buenos Aires. Ha contribuido con la apertura de 34 escuelas de espectadores en diversos países, la más reciente en Francia.
} 


\begin{abstract}
The Comparative Theater and the concepts of territoriality, inter-territoriality, intra-territoriality and supra-territoriality enable a new design of the theatrical cartography, demanded today by the indispensable updating of the Theatrology. Territoriality considers theater in geographical-historical-cultural contexts of relationship and difference when they are contrasted with other contexts. There are two fundamental types of theatrical territoriality: a geographical territoriality and a corporal one. The comparative territoriality is conceived as a subjective space, a space constructed from processes of territorialization (processes of subjectivation), de-territorialization and re-territorialization. As an example of intraterritorial complexity, this article analyzes the responses of spectators in Buenos Aires, in 2013, to the concept of «commercial art theater».

\section{Keywords}

Comparative Theater · Territoriality · Space · Subjectivity. Spectators
\end{abstract}

En una segunda etapa de redefinición teórica, iniciada en los albores del siglo XXI (Dubatti, 2011), el Teatro Comparado introdujo el concepto de territorialidad (y sus derivados: interterritorialidad, supraterritorialidad e intraterritorialidad; territorialización, desterritorialización y reterritorialización) para superar el marco de lo nacional (y sus derivados: internacional, supranacional, intranacional, etc.). Lo nacional puede ser pensado desde la territorialidad, pero no todas las territorialidades se relacionan con lo nacional. Así, el comparatismo teatral ganó una herramienta a favor de la intelección de la multiplicidad, como pide Claudio Guillén, en virtud de la «tarea diferencialista del amor que consiste en encontrar lo irrepetible» (1998:17). Territorialidad permite enmarcar zonas diversas, más amplias y/o más acotadas que lo nacional.

La territorialidad considera los acontecimientos teatrales en contextos geográficohistórico-culturales de relación y diferencia cuando se los contrasta con otros contextos. Sigue válida la fórmula comparatista clásica X-Y. La territorialidad comparatista se vincula con el pensamiento de la Geografía Humana (Hiernaux y Lindón, 2006). Territorialidad es espacio subjetivado, geografía en la que se configura una determinada subjetivación, espacio construido a partir de procesos de territorialización, es decir, procesos de subjetivación. Reconoce complejidades intraterritoriales dentro de un mismo territorio (nunca monolítico u homogéneo). Geografía subjetivada, siempre en transformación, porque la territorialización incluye las tensiones de la desterritorialización y la reterritorialización. Ya Ricardo 
Rojas, en 1907, en su notable El país de la selva, insta a escribir una "geografía espiritual de la República» (2004:138). Lo territorial nunca está aislado, salvo que lo clausuren e incomuniquen algunos «ismos» ${ }^{1}$. Como afirmó Paul Vidal de La Blache para la Geografía Humana: «La Tierra es un todo cuyas partes están coordinadas (...), en el organismo terrestre no existe nada en forma aislada» (1922:3). Territorialidad implica siempre un espesor de planos conectados, un espesor de mapas de multiplicidad compleja: zona de atravesamientos inter/intra/ supraterritoriales, en procesos de re/des/territorialización.

Destaca Robert T. Tally Jr. que en 1967 Michel Foucault anunciaba en «Des espaces autres» una «era del espacio»:

La gran obsesión del siglo XIX ha sido, como sabemos, la historia, con sus temas del desarrollo y la interrupción, de la crisis y el ciclo, de la acumulación del pasado, con su exceso de hombres muertos y el amenazante enfriamiento del mundo. [...] La época presente acaso sea por encima de todo la época del espacio. Estamos en una era de lo simultáneo: estamos en la era de la yuxtaposición, la era de lo cercano y lejano, del lado a lado, de lo disperso. Pienso que estamos en un momento en que nuestra experiencia del mundo es menos la de una vida extensa desarrollándose a lo largo del tiempo que la de una red que conecta puntos y entrecruza su propia madeja. (Foucault, 1986:22, citado por Tally, 2015:77, traducción de M. García)

Tally comenta que, de acuerdo con Foucault, «las relaciones espaciales no son meramente un decorado o telón de fondo de los acontecimientos, un contenedor vacío para ser llenado con acciones o movimientos, o algo para ser tratado como «lo muerto, lo fijo, lo no dialéctico, lo inmóvil» (Foucault: 1980:70). Concluye Tally refiriendo a Henri Lefebvre (La producción del espacio, 1991): «El espacio es tanto producto como producción: de hecho nos produce a nosotros» (2015:78).

A la supraterritorialidad corresponden aquellos fenómenos o conceptos que no pueden ser pensados en términos territoriales porque los superan o exceden; a la interterritorialidad, aquellos que conectan dos o más territorialidades reconocibles; a la intraterritorialidad, la consideración de la multiplicidad de territorios dentro del mismo territorio.

El geógrafo finlandés Anssi Paasi, con amplia bibliografía sobre los problemas territoriales, afirma sobre la complejidad del concepto de territorio que, en un sentido geográfico, debe ser distinguido de otros usos «metafóricos» (2003:109). El comparatismo teatral sigue la noción geográfica y estudia los fenómenos teatrales desde el punto de vista de su manifestación territorial (geográfico-histórico-cultural-subjetiva): planeta, continente, país, área, región, ciudad, pueblo, barrio, sala o espacio teatral, la zona del acontecimiento teatral, etc., por relación y contraste con otros fenómenos territoriales y/o por superación de dicha territorialidad. Los fenómenos territoriales pueden ser localizados geográfico-histórico-culturalmente $y$, en tanto teatrales, constituyen mapas específicos que no se superponen con los mapas políticos (mapas que representan las divisiones políticas y administrativas) y se diferencian especialmente de los mapas de los estados-nación. La territorialidad del teatro compone mapas específicos de Geografía Teatral que no se superponen necesariamente con los mapas de la Geografía Política, y dialogan con ellos por su diferencia. La culminación del Teatro Comparado es, en consecuencia, la elaboración de una Cartografía Teatral, mapas específicos del teatro, síntesis del pensamiento territorial sobre el teatro. 
Según Alvaro Bello (Etnicidad y ciudadanía en América Latina. La acción colectiva de los pueblos indígenas), «el territorio tiende a ubicarse sobre el espacio, pero no es el espacio, sino más bien una "producción" sobre este. Esta producción es el resultado de las relaciones y, como todas las relaciones, ellas están inscriptas dentro de un campo de poder» (2004:99). El Teatro Comparado piensa los vínculos teatrales en relaciones territoriales de poder en permanente mutación. Mariano García, María José Punte y María Lucía Puppo afirman que «hoy el espacio ya no puede ser asumido como una estructura fija e inamovible. Debe ser comprendido, más bien, como parte de un proceso dinámico y nunca acabado, que tiene que ver con múltiples lógicas regionales, nacionales, continentales y mundiales» (2015:15).

Un territorio es siempre un fenómeno complejo por su diversidad interna y por su dinamismo, su permanente transformación. Las identidades territoriales, a diferencia de cómo las piensan los estados-nación, y especialmente los «ismos» de los nacionalismos, nunca están cristalizadas ni responden a una esencia inmutable. Sin embargo, esto no significa que no podamos definir identidades en los territorios; podemos hacerlo siempre que se trate de identidades dinámicas, complejas, múltiples. En un examen del pensamiento de Rogerio Haesbaert $(O$ Mito da Desterritorializaçao. Do "fin dos territorios» à multiterritorialidade, 2004), César A. Gómez y María Gisela Hadad afirman que «concibe al territorio como el resultado de un proceso de territorialización que implica un dominio (aspecto económico-político) y una apropiación (aspecto simbólico-cultural) de los espacios por los grupos humanos» (2007:6). Y agregan: «El territorio debe ser pensado como la manifestación objetivada de una determinada configuración social, no exenta de conflictos que involucran a una diversidad de actores que comparten el espacio» (2007:8). De allí que debamos reconocer complejidades intraterritoriales y mutaciones en lo geográfico-subjetivo. Incluso la globalización debe ser concebida como una manifestación territorial, geográfico-subjetiva. Para Boaventura De Sousa Santos, la globalización es siempre la globalización exitosa de un fenómeno local dado. En «Nuestra América. Reinventando un paradigma subalterno de reconocimiento y redistribución», De Sousa Santos afirma:

En otra palabras, no existe condición global alguna para la que no podamos hallar una raíz local, un fondo cultural específico (...) Y aquí mi definición de globalización: el proceso por el cual una condición o entidad local dada logra extender su alcance por todo el globo y, al hacerlo, desarrolla la capacidad de designar como local a alguna entidad o condición social rival. (De Sousa Santos, 2001)

En un sentido complementario, Rita Segato (2002) pone el acento en la globalización y sus procesos de desterritorialización, pero señala que al mismo tiempo genera, paradójicamente, homogenización y diversificación territorial.

Los procesos de territorialización, desterritorialización y reterritorialización pueden observarse en múltiples fenómenos. Buenos Aires, en tanto campo teatral, compone un territorio de grandes transformaciones si se confrontan sus diferentes descripciones sincrónicas y se las proyecta en el eje diacrónico (Dubatti, 2012): hay diversos teatros porteños en la historia. Nuestro vínculo subjetivo con un espacio cambia históricamente: la Facultad de Filosofía y Letras de la Universidad de Buenos Aires no fue para nosotros el mismo territorio la primera vez que lo pisamos como alumnos ingresantes, o cuando empezamos a dar clases en ella muy 
jóvenes, o tras 35 años de docencia; así también, la relación de los teatristas con una sala no es la misma, en términos de subjetivación territorial, cuando la abren o en los distintos momentos de configuración de una trayectoria.

Territorialización, desterritorialización y reterritorialización se perciben omnipresentes. Un actor formado en Buenos Aires por el método de las acciones físicas según Raúl Serrano viaja a Estados Unidos a estudiar con Lee Strasberg: allí su vínculo con Stanislavski se desterritorializa de las enseñanzas de Serrano y reterritorializa en la experiencia norteamericana, y al regresar a Buenos Aires empieza a concebir y trabajar un actor stanislavskiano diferente. Pensemos en los espectadores: imaginemos una escena del pasado, en 1896, en la que un espectador porteño aplaude el estreno de Calandria, del nativista Martiniano Leguizamón, derivación domesticada de la gauchesca teatral, y luego viaja a Francia para asistir en París al estreno de Ubú Rey, de Alfred Jarry, génesis de la vanguardia. ¿¿Cómo repensaría ese espectador finisecular Calandria desde Ubú Rey, el teatro rioplatense desde el teatro francés, y el teatro en general entre esos extremos? En 2018 desde la crítica y la investigación visitamos el campo teatral de París y formulamos algunas observaciones territoriales sobre la escena francesa, que se descompusieron y reformularon cuando nos trasladamos a Lille (cerca de Bélgica) y tomamos contacto con un campo teatral muy diverso al parisino, para luego irnos a trabajar a La Rochelle (al Oeste, frente al mar). Territorializamos, desterritorializamos y reterritorializamos nuestra idea del teatro francés actual en un proceso permanente de transformación y dinamismo, que muta cada vez que realizamos un nuevo contacto directo, recibimos información o leemos nueva bibliografía al respecto. Nuestras representaciones territoriales se modifican. Lo mismo nos sucede cuando vamos recorriendo diferentes campos teatrales de la Argentina, en las provincias, con estructuras económico-políticas, historias y apropiaciones simbólico-culturales diferentes: nuestra idea de los «teatros argentinos» y sus interrelaciones va mutando constantemente a partir de los datos, las experiencias, las categorías teóricas que vamos poniendo en juego en la extensión del país. Cada territorio nos exige procesos de desterritorialización (respecto de nuestros saberes territoriales anteriores) y de reterritorialización (a partir de un trabajo de selección e integración).

En consecuencia, no hay que confundir territorialidad con establecerse en un lugar o sedentarismo. La itinerancia, el camino, también son territorio, como lo demuestra Haroldo Conti en su novela Mascaró y la presencia del Circo del Arca en su derrotero: «La vida es una entera travesía, se erraba desde el nacimiento» (1993:63). Oreste afirma que solo le interesa «andar de un lado a otro» y El Príncipe apunta al carácter único de cada experiencia de itinerancia: «Hay formas de hacerlo. Mascaró lo hace de una, tú de otra. Creo que lo importante es hacerlo con alegría» (1993:76). Viaje es territorialidad en todos sus ángulos cartográficos y dinámicos. La relevancia de la territorialidad se impone en el hacer teatral, desde una razón de la praxis, aunque se intente negarlo teóricamente desde una razón lógica (abstracta, geométrica, matemática) o desde una razón bibliográfica². Incluso nuestra forma de comprender los términos teóricos es territorial. El cuerpo en el espacio impone la experiencia de la territorialidad. La dramaturga-actriz Andrea Garrote, en su pieza Pundonor, imagina a una profesora de Historia de la Filosofía que intenta dar una clase sobre el pensamiento de Michel Foucault. La anécdota es, en un punto, un pretexto para hablar metateatralmente sobre uno de los fundamentos del teatro-matriz: el cuerpo. «Para escapar necesitamos el cuerpo. Porque si alguno de 
ustedes fantasea con que el humano que sobreviva evolucionará hacia una mente sin cuerpo, en realidad fantasea con la muerte total del humano» (2019:32). La territorialidad del cuerpo es su materialidad espacial, inseparable de lo humano / lo teatral, como afirma la Filosofía del Teatro (Dubatti, 2016).

Filosóficamente sostenemos que el teatro no se puede desterritorializar. Si se lo desterritorializa, deja de ser acontecimiento teatral. Al menos dos conexiones raigales, insoslayables, establecen la fusión del teatro con la territorialidad: el cuerpo y el convivio ${ }^{3}$. El cuerpo del actor y el cuerpo del espectador, como parte y contigüidad de la materialidad del espacio real, siempre ubicados en una encrucijada geográfico-histórico-cultural; el convivio, reunión de cuerpos presentes, en presencia física, porque acontece necesariamente en una intersección del espaciotiempo reales. Teatro y tierra están intrínsecamente asimilados: el teatro es terreno, terrestre, terráqueo, territorial. En el teatro nos reunimos con el otro de cuerpo presente. El teatro es el otro humano, afirma la Filosofía del Teatro. Geografía subjetivada es la zona que se construye con el otro.

Cuando proponemos una definición pragmática del teatro en tanto acontecimiento, hablamos de una zona de experiencia y subjetivación que surge de la multiplicación de convivio + poíesis corporal + expectación en el acontecimiento. Esa zona siempre está ubicada en un espacio geográfico, allí donde acontece el acontecimiento. Debemos trasladarnos a ella (no podemos formar parte de la zona a distancia, en el mejor de los casos solo recibimos información, como cuando vemos en internet un videoteatro), nos exige un vínculo socioterritorial. En este sentido, Néstor García Canclini (1995:17-21) distingue las prácticas territorializadas, a las que se exigen relaciones socioespaciales (sociogeográficas), de las prácticas desterritorializadas, que se producen en el espacio virtual por vínculos sociocomunicacionales. Si queremos leer la edición de las obras completas de Sartre las podemos bajar de internet (porque la tecnología de la literatura admite la desterritorialización), pero si queremos experimentar el acontecimiento teatral de una puesta de $A$ puerta cerrada, valga el caso, en Madrid, no queda otra opción que viajar a la capital española, o esperar que dicha puesta viaje a un lugar donde podamos vivirla en convivio territorial.

Hay sin duda una dimensión desterritorializada del acontecimiento teatral (el aspecto abstracto de la poiesis, metáfora, estructura imaginaria, espacio poético «infinito» de acuerdo con la directora Lía Jelín, 2018), pero, como afirma la Filosofía del Teatro, por las características del acontecimiento teatral, no puede sino encarnarse en la territorialización: en el teatro la poíesis es corporal, en consecuencia hay un espacio de liminalidad entre territorialidad y desterritorialización, pero esta última depende de la territorialidad del cuerpo en convivio para producirse. En el teatro no hay espacio poético sin cuerpo ni convivio. En el teatro hasta la desterritorialización está territorializada. La del teatro no es la desterritorialización sociocomunicacional del tecnovivio (transmisión de información por vía digital y máquinas al margen de la materialidad del cuerpo viviente, gracias a una tecnología que permite la sustracción del cuerpo presente), sino la territorialización subjetivo-socio-espacial del convivio. Los signos se pueden transmitir sociocomunicacionalmente, pero la materialidad del cuerpo no. En el teatro la desterritorialización es una práctica territorializada por el cuerpo y el convivio. No hay un teatro transterritorial, o extraterritorial, sino, en el mejor de los casos, componentes de desterritorialización poiética territorializados por las prácticas corporales y espaciales del acontecimiento 
convivial. De allí la diferencia entre expectar poíesis corporal humana, viviente, o poiesis artificial de los hologramas, proyecciones, robots. O la diferencia entre ver teatro y ver videoteatro ${ }^{4}$.

Así podemos distinguir dos tipos fundamentales de territorialidad teatral: la territorialidad geográfica, que opera poniendo el eje en los contextos espacio-histórico-culturales, la encrucijada espacio-temporal, y la territorialidad corporal, que se centra en la capacidad del cuerpo de portar consigo las territorialidades con las que se identifica y se ha nutrido culturalmente. Por eso el Teatro Comparado piensa en relaciones complejas de tensión con la Geopolítica y la Corpopolítica.

La migración de un agente (unidad corporal territorial) de un territorio a otro implica la conexión con nuevos sistemas complejos territoriales que refuncionalizan y resemantizan dicho agente al conectarlo con un sistema otro de relaciones. ¿Quiénes somos en el campo teatral de Buenos Aires y quiénes en el campo teatral de Barcelona? Somos diferentes porque los sistemas complejos territoriales son diferentes. En el documental La maleta mexicana (2011), de la directora Trisha Ziff, el escritor mexicano Juan Villoro rescata enfáticamente la relevancia territorial y expresa su oposición a la tendencia contemporánea de «despojar los hechos del contexto", rechaza que "se los sustrae a una especie de galaxia cosmopolita en la que no importan los lugares, las tramas, las narrativas que los explican». En el teatro sus palabras son especialmente acertadas.

Que la zona de experiencia y subjetivación del acontecimiento es territorial (encrucijada geográfico-histórico-cultural) queda claro cuando no podemos ingresar hasta ella (por ejemplo, porque no nos permiten la entrada a la sala, hemos llegado tarde y el espectáculo ya empezó) o cuando por alguna razón debemos retirarnos del convivio. Es común, cuando uno va con niños a una función teatral, que en medio del acontecimiento pidan ir al baño: uno debe levantarse con su nieto, salir de la sala, se pierde el contacto con la zona, y al regresar cuesta volver a vincularse. ¿De qué se ríen los espectadores, quién es ese nuevo personaje que ha ingresado, qué ha pasado durante el lapso en que debimos ausentarnos? La reconexión territorial con la zona de acontecimiento es progresiva. Por otra parte, la zona es intransferible: si llegamos tarde a una función y no pudimos acceder a la sala, esperaremos a nuestros amigos (que sí pudieron entrar) en un bar, averiguaremos el horario de finalización y los reencontraremos en la calle a la salida del teatro. Salen afectados por la zona en la que participaron. Pronto advertiremos que esa afectación no puede sernos transmitida ni legada. Experimentamos una extraña ajenidad, un sentimiento de exclusión, ¡de envidia porque ellos sí entraron!, percibimos la excepcionalidad existencial de quienes accedieron al acontecimiento. Solo nos queda resignarnos a recibir algo de información (balbuceante, incompleta, elíptica) sobre una zona que, además, ya no existe y es irrecuperable. $Y$ asumir la promesa de una nueva oportunidad (en la que ya no experimentaremos lo que ellos experimentaron).

Nos interesa valorizar el término «zona» tal como es planteado por Juan José Saer en sus relatos del libro En la zona (1960) y La mayor (1976). Según la comparatista argentina Adriana Cristina Crolla, el uso que da Saer al término «posibilita un ejercicio crítico, acrobático, estético y comparado, localizado y al mismo tiempo expandible» (2012:94) para el estudio de las territorialidades, «más allá de cualquier frontera y delimitación ortodoxa» (102). Siguiendo al martiniqués Édouard Glissant y a la colombiana Amalia Boyer (2009), Crolla propone una Geoestética como paradigma ético-estético. Para pensar la Pampa Gringa (italiana) en la provincia 
de Santa Fe (fenómeno intranacional, intraterritorial, dentro de la Argentina, y al mismo tiempo internacional, interterritorial) como «una gran zona cultural, geográfica y matricial foránea» (2012:102), Crolla reflexiona:

El espacio más que una realidad física tangible debe ser concebido como un conjunto de formas representativas de relaciones o como una estructura representada por formas sociales que se manifiestan por medio de procesos, funciones y apropiaciones. Un medio de acción y relación del hombre con lo real y con los otros con los que comparte una ubicación perimetrada por coordenadas geográficas, pero en la que se constituyen sistemas a partir de dimensiones culturales, económicas y sociales. (2012:91)

La construcción de esa zona depende de operaciones «implícitas, afectivas y connotativas, no del todo conscientes» (Mandoki, 2006:71), mundo experiencial, corporal, afectivo, en términos de Guattari y Rolnik, de subjetivación. La zona de experiencia que constituye el teatro es un espacio de subjetivación, o una «máquina de producción de subjetividad» (Guattari-Rolnik, 2006:37). Llamamos subjetividad a las formas de estar en el mundo, habitarlo y concebirlo generadas, portadas y transmitidas por los sujetos históricos, por extensión a la capacidad de producir sentido de dichos sujetos. Subjetividad es un concepto más abarcador que el de ideología (programa consciente), en tanto involucra o atraviesa todas las dimensiones de la vida humana (incluso las no concientizadas) porque opera como «la modelización de los comportamientos, la sensibilidad, la percepción, la memoria, las relaciones sociales, las relaciones sexuales, los fantasmas imaginarios, etc.» (Guattari-Rolnik, 2006:41).

La territorialidad, en tanto zona geográfico-histórico-cultural de subjetivación, se inscribe en todos los planos del acontecimiento teatral, no solo en el convivio con actores-técnicos-espectadores, sino también en todos los niveles de la poética del espectáculo (como estudiamos en Terrenal, de Mauricio Kartun, Dubatti, 2019b). Hay además plena conciencia del dramaturgo respecto de cómo opera esa territorialidad en los procesos de escritura (véase la entrevista incluida en Kartun, 2014:69-83). La percepción de la relevancia territorial de los componentes señalados se verticaliza cuando se advierte su reformulación en la puesta en escena / reescritura brasileña de Terrenal, presentada en San Pablo, Brasil, 2018-2019, con dirección de Marco Antonio Rodrigues y traducción de Cecilia Boal5.

En términos de teoría poética, la territorialidad se encarna en todos los niveles de la poética: en las estructuras, en el trabajo, en las concepciones y en la pragmática de relación con los espectadores. Incluso el borramiento de ciertas marcas culturales de territorialidad, paradójicamente, puede constituir otra forma de ratificación territorial (como ha propuesto Jorge Luis Borges en «El escritor argentino y la tradición», en Discusión, donde sostiene con Gibbon que no hay camellos en el Alcorán, «el libro Árabe por excelencia», 2007:320). "Nuestro patrimonio es el universo» (2007:324): Borges diseña una forma intraterritorial de diferenciarse de otras opciones del mismo contexto (por ejemplo: el nacionalismo, el realismo, la gauchesca, el casticismo).

Traspolando propuestas de Michel Collot (2015) para la literatura, se pueden distinguir en el Teatro Comparado tres grandes áreas de estudio interrelacionadas: Geografía Teatral, Geocrítica y Geopoética. Collot propone 
una mejor integración de la dimensión espacial en los estudios literarios [teatrales], en tres niveles distintos pero complementarios: el de una geografía de la literatura [del teatro], que estudia el contexto espacial en el que se producen las obras, y que se sitúa en el plano geográfico, pero también histórico, social y cultural; el de una geocrítica, que estudia las representaciones del espacio en los textos mismos, y que se sitúa más bien en el plano del imaginario y de la temática; el de una geopoética, que estudia los vínculos entre el espacio y las formas y los géneros literarios, y que puede desembocar en una poética, una teoría de la creación literaria. (2015:62-63).

El comparatismo surge cuando se problematiza la territorialidad, ya sea por vínculos topográficos (de pertenencia geográfica a tal ciudad, tal región, tal país, tal continente, de relocalización, traslado, viaje, exilio...), de diacronicidad (aspectos de la historicidad en su proyección en el tiempo), de sincronicidad (aspectos de la historicidad en la simultaneidad), de superación de la territorialidad (cuando la problematización de lo territorial concluye en un planteo supraterritorial). No hay comparatismo cuando la territorialidad se da por sentada, como un fenómeno dado o a priori, o cuando se la ignora sin problematización. La supraterritorialidad debe ser conclusión del ejercicio de problematización de la territorialidad, no de su ignorancia. La territorialidad topográfica implica la localización de los fenómenos teatrales en sus respectivos contextos geográficos teatrales-culturales a partir de un corte histórico determinado (caso: la dramaturgia de Henrik Ibsen en Buenos Aires). La territorialidad diacrónica observa fenómenos de sucesión, estabilidad y cambio en el tiempo (relaciones y diferencias entre el Ibsen de Buenos Aires en 1900 y en 1910). La territorialidad sincrónica reconoce fenómenos de simultaneidad y coexistencia (Ibsen en Buenos Aires y en Córdoba). La supraterritorialidad señala aquellos fenómenos que superan las encrucijadas geográfico-histórico-culturales, por ejemplo, la construcción de las poéticas abstractas o poéticas teóricas (la presencia en la Argentina de una idea del drama moderno más allá de la lectura o la puesta en escena de Ibsen).

La territorialidad del comparatismo es una herramienta eficaz para el estudio de los campos teatrales. Por ejemplo, para el análisis del público. Un caso fascinante de multiplicidad intraterritorial es el de los espectadores de Buenos Aires, el de sus formas diversas de relacionarse con las dinámicas del campo e interpretar un espectáculo. Los espectadores han sido en la historiografía teatral casi una omisión (Dubatti, 2019c) y debemos detenernos en su complejidad. Basta determinar un eje de investigación para advertir la diversidad intraterritorial de sus posicionamientos. Tomemos el eje teatro comercial de arte. Llamamos así a un teatro de calidad, diverso en sus poéticas y dotado de importante presupuesto de producción, gestado con inversiones de empresarios (sin apoyo del Estado), en el que trabajan actores de relevante trayectoria y valiosos equipos creativos en todos los rubros: dirección, escenografía, música, iluminación, vestuario, etc. De acuerdo con el monto de la inversión realizada y con la voluntad comercial de recupero y multiplicación de dinero en la taquilla, el precio de las entradas es alto, mucho más del doble, el triple, el cuádruple o el quíntuple de lo que cuesta una entrada a los espectáculos producidos por el teatro oficial (Teatro Nacional Cervantes, Complejo Teatral de Buenos Aires y otros) o por los grupos independientes. Algunos casos destacables de este teatro de arte en los últimos años han sido Filosofía de vida, de Juan Villoro, con Alfredo Alcón y dirección de Javier Daulte, y 33 variaciones, de Moisés Kaufman, con Marilú Marini y Lito Cruz, dirigido por Helena Tritek, en el Metropolitan 2; Master Class, de Terrence McNally, con Norma Aleandro, dirección de Agustín 
Alezzo, en el Maipo; La cabra, de Edward Albee, con Julio Chávez en el Tabarís; Amadeus, de Peter Shaffer, con Oscar Martínez y Rodrigo de la Serna, dirigidos por Javier Daulte, en el Metropolitan 1; La última sesión de Freud, con Jorge Suárez y Luis Machín, dirección de Daniel Veronese, en el Multiteatro, entre muchos. Una vez que dejan de presentarse en Buenos Aires, estos exponentes de teatro comercial de calidad salen en gira y se siguen presentando en funciones repletas en salas de gran capacidad en las provincias. Hay que diferenciar estas expresiones de las de un teatro comercial de mero entretenimiento y baja calidad, con el que contrastan por la trascendencia de sus textos, sus puestas y actuaciones. Para muchos, la denominación teatro comercial de arte funciona como un «oxímoron», reunión de opuestos inconciliables. Según la tradición radicalizada del teatro independiente, fundada en $1930 \mathrm{y}$ tan fuerte en Buenos Aires hasta hoy, si algo es comercial no puede ser de arte, y viceversa. Sin embargo, la realidad del campo teatral porteño demuestra lo contrario. ¿Hay un prejuicio contra el teatro comercial? Históricamente, la preocupación por producir un teatro comercial de arte nace ya en la Argentina en los años veinte y se consolida, en los treinta y cuarenta, con la obra de grandes compañías en las que participan Armando Discépolo, Luis Arata, Pepe Arias, Paulina Singerman, Mecha Ortiz, Lola Membrives, Gloria Ferrandiz, Samuel Eichelbaum, entre muchos otros. Buscan vivir profesionalmente haciendo obras de calidad artística. Así lo expresa Federico García Lorca en su visita a Buenos Aires: en sus palabras de homenaje a Lola Membrives en el Teatro Comedia (16 de marzo de 1934), el gran poeta español señala que el teatro

ha perdido su autoridad porque día tras día se ha producido un gran desequilibrio entre arte y negocio. El teatro necesita dinero, y es justo y fundamental para su vida que sea motivo de lucro, pero hasta la mitad nada más. La otra mitad es depuración, belleza, cuido (sic), sacrificio por un fin superior de emoción y cultura. (2008, VI:419)

Para García Lorca, el secreto es poner ingresos laborales y arte en equilibrio. Más allá de sus méritos, el teatro comercial de arte presenta, en rasgos generales, tres grandes problemas: ofrece tiempos acotados de producción, que muchas veces aceleran los procesos y limitan la necesaria investigación y búsqueda en los ensayos; casi no considera las obras de autores nacionales, y la mayoría de los textos son de autores extranjeros y responden a grandes estrenos en Nueva York, Londres o París o a dramaturgias de probada sucursalización; por último, excluye a aquellos espectadores que no pueden pagar las entradas, especialmente los estudiantes, los trabajadores más humildes, los jubilados.

¿Qué piensan los espectadores al respecto? Tomando la base de datos de una encuesta que realizamos en $2013^{6}$, en el mismo territorio del campo teatral porteño, la diversidad intraterritorial es inocultable. Baste, a manera de muestra, transcribir algunas declaraciones de los espectadores. Irene (escribana, 70 años) asegura: «Me maravillan los progresos que ha tenido este teatro. Lejos de los costos que esto significa, también se presentan alternativas de descuentos interesantes». Dora (psiquiatra y psicoanalista, 65) observa que en 2013 vio en el teatro comercial de arte obras que le interesaron y que, a pesar de los precios, «como somos amantes del teatro, concurrimos y a veces debemos privarnos de otras cosas». Graciela (empleada, 52) destaca a los actores «conocidos de la televisión» que impulsan a un público masivo a tomar contacto con grandes textos como Las brujas de Salem, de Arthur Miller. 
De esta manera, adolescentes y adultos se acercan al teatro por primera vez. No importa si van a buscar a los personajes que ven en televisión y se encuentran con otros muy alejados de esos. Lo que importa es lo que descubren: el teatro. Así acceden a valiosos textos.

Ángel (contador, 73) recuerda a Leónidas Barletta, fundador del teatro independiente, gran enemigo del teatro comercial:

Para Barletta estoy seguro que estas palabras, «teatro comercial de arte», serían un oxímoron, una paradójica reunión de opuestos. Y muy lejos no estaría dado que según la Real Academia Española comercial es lo perteneciente o relativo al comercio o a los comerciantes, y arte es la actividad humana mediante la cual se expresa una visión personal y desinteresada que interpreta lo real o imaginado con recursos plásticos, lingüísticos o sonoros. La contemporaneidad en que nos toca vivir está transformando la visión de muchas cosas y hasta podemos llegar a comprender que para tener acceso a las nuevas técnicas (sumado el afán de lucro) se deben entornar los párpados y dejar hacer. Pero en medio de estos dos conceptos está el espectador, ese que súbitamente despierta del sueño de Don Leónidas y la ensoñación de los nuevos efectos, sacudido por el precio de las entradas... Ahora me pregunto: ¿¿cómo congeniar estas dos verdades?

Silvia (docente jubilada, 63), que viene de la Patagonia y vive en Buenos Aires, rechaza esta forma de producción teatral:

Me sucede que, en general, siento que asisto a un espacio de televisión en vivo. Los mismos modos de actuación, temáticas poco interesantes. Algo pre-digerido, masticado para ser aceptado, no molestar y ser entendido sin un mínimo esfuerzo. El público me altera por su modo de estar presente en el hall del teatro y aun cuando transcurre la obra. En general es más ruidoso... Está ausente el silencio sagrado de comunión que sí siento en el independiente casi siempre. Ir a un teatro comercial es como ir a comer a McDonald's. Cuando voy al teatro independiente siento amor. Me produce ternura ver esa gente joven y no tanto jugándose el pellejo en propuestas que son atrevidas.

Tres visiones más. Patricia (empresaria, 54):

Veo un montón de obras, las de la calle Corrientes también, y por supuesto las que más me interesan y me aportan son las que no están ahí. Es verdad que hay cambios, pero sutiles, que todavía no pueden ni compararse al aporte del circuito independiente.

Elsa (empleada, 57) da su visión:

El teatro comercial incluye obras excelentemente actuadas, con temáticas muy variadas, buenas escenografías, etc., pero hay dos puntos con los cuales no estoy de acuerdo. La gran mayoría de obras son de autores extranjeros, sería ideal que se utilizaran obras de autores nacionales, que los tenemos y muy buenos. De esa forma, quizás, las temáticas serían más afines a nuestras vivencias y costumbres. Otro gran detalle es el costo de las entradas, son para una verdadera élite de espectadores, el común de la gente, que gusta del buen teatro, tiene dificultades para comprar localidades de esos valores, quizás tendrían que tener descuentos a jubilados y estudiantes con algún tipo de acreditación.

Finalmente, para cerrar este breve relevamiento, Antonio (empresario, 74): 
El teatro comercial está pasando por una etapa muy rica. Para llegar a esta conclusión basta con observar las marquesinas de la calle Corrientes, la cantidad de público que asiste y el nivel artístico de las propuestas. No obstante advierto que existen factores que condicionan al espectáculo subordinándolo al bordereau (la recaudación) y ello produce cierto distanciamiento que afecta el convivio teatral. Tal vez mi opinión esté atravesada por prejuicios, pero en algunas ocasiones me he sentido tratado como un cliente al que se le quiso vender un producto. Esto no aparece en el teatro oficial ni en el teatro independiente y creo que el teatro comercial está en condiciones de alcanzar las mismas metas.

Con sus diferencias y matices, las opiniones de los espectadores son sin duda relevantes, ya que es la afluencia caudalosa de público la que sostiene este tipo de teatro. Esta multiplicidad intraterritorial no escapa a otros aspectos de la vida social y cultural en general. Las competencias y los comportamientos de los espectadores, vinculados a los territorios teatrales que frecuentan, ponen en primer plano la experiencia territorial. Esto se observa nítidamente en las Escuelas de Espectadores: si se confrontan las 34 escuelas abiertas hasta hoy (varias en la Argentina y en México, y al menos una en Bolivia, Brasil, Chile, Colombia, Costa Rica, Ecuador, España, Francia, Perú, Uruguay, Venezuela), son todas muy diferentes en sus dinámicas, composición y permanencia. Las características de los espectadores están ligadas al teatro que frecuentan en sus territorios. Resulta reveladora la tesis doctoral de Olivia Camboim Romano (2018), donde compara las escuelas de espectadores de Buenos Aires y Porto Alegre. De la misma manera, los testimonios de los distintos coordinadores de las escuelas, reunidos en los dossiers de la revista mexicana Paso de Gato (Dubatti, coord., 2017 y 2019d), ilustran esa diversidad. En la Argentina sobresale la experiencia de la Escuela de Espectadores en las cárceles de Devoto y Ezeiza, con un ejercicio territorial muy diverso al de las escuelas abiertas para todo público (como escribe Ana Groch en Dubatti, 2017:37-38). La «zona» que se construye en las escuelas de espectadores cambia intraterritorialmente según el campo teatral, la composición de coordinación y el alumnado (niños, adolescentes, adultos, presidiarios, público de festivales, enfermos en hospitales...), la pertenencia institucional (públicas o privadas), la especialización (artes escénicas, danza, artes en general), y por supuesto, la singularidad de cada alumno y cada coordinador. En términos de territorialidad corporal, cada espectador y cada coordinador traen consigo su territorialidad al convivio. Cambia el convivio y cambia la intraterritorialidad del acontecimiento. Esta es una de las razones por las que no hay una función teatral igual a otra, ni ninguna clase o sesión de escuela de espectadores igual a otra. En los fenómenos teatrales, en suma, el concepto de intraterritorialidad ilumina una multiplicidad que recién empezamos a problematizar y que también debemos reconocer en la historia del teatro.

Notas

${ }^{1}$ Hablamos de territorialidad y no de territorialismos: ni localismos cerrados, ni universalismos de entelequia. Comprendamos los «ismos» como usos políticos de la territorialidad para favorecer una determinada 
visión ideológica o tendencia cultural, sin duda respetables, pero que instalan otras problemáticas. Como señala Ana María Barrenechea para pensar «lo peculiar y lo universal» en la obra del maestro dominicano Pedro Henríquez Ureńa: «ni nacionalismos telúricos, ni ampulosidad hispanizante, ni cosmopolitismo frívolo» (1984: 21).

${ }^{2}$ Para una distinción entre razón de la praxis, razón lógica y razón bibliográfica, véase Dubatti, 2019a.

${ }^{3}$ Oponemos a convivio la noción de tecnovivio, experiencia mediada por las tecnologías que permiten la sustracción de la presencia física del cuerpo del otro en la misma territorialidad y admiten relaciones remotas, a distancia, interterritoriales o desterritorializadas (el libro, el cine, la televisión, la radio, el teléfono, la web, las redes ópticas, la comunicación satelital, etc.). Véase Dubatti, 2014: 123-136. El convivio tiene un límite territorial concreto: una sala, una plaza, una cancha, una zona, y es por lo tanto necesariamente minoritario si se lo comparada con el tecnovivio, que puede llegar a millones y millones de personas (por ejemplo: en la ceremonia de los "Oscar», están en convivio quienes están presentes en la sala de la ceremonia, y en tecnovivio millones de televidentes que ven la ceremonia por televisión). Convivio y tecnovivio producen zonas de experiencia diversas, ni mejores ni peores: diferentes. Hay cruces, fusiones, puestas en suspenso de las diferencias, liminalidades: convivios atecnoviviados, convivios que incluyen tecnovivio, alternancias, etc. Por eso hablamos de teatro-matriz y teatro liminal (Dubatti, 2016), para teorizar esos cruces. El convivio teatral puede incluir lo tecnovivial, pero en el teatro lo tecnovivial no puede desplazar ni anular el convivio, sino integrarse a este.

${ }^{4}$ La cuarentena obligatoria contra la pandemia del coronavirus en 2020 puso en primer plano la diferencia de estas experiencias: cierre de las salas teatrales y de todo espacio de reunión, y proliferación de videoteatros en la web.

${ }^{5}$ Sugerimos al lector que confronte las fotografías de escena de ambos espectáculos, argentino y brasileño, disponibles en la web.

${ }^{6}$ Disponible en nuestro archivo.

\section{Referencias bibliográficas}

Barrenechea, A.M. (1984). Lo peculiar y lo universal en la América de Pedro Henríquez Ureña. Sur (355), 21-24.

Bello, Á. (2004). Etnicidad y ciudadania en América Latina. La acción colectiva de los pueblos indígenas. CEPAL.

Borges, J.L. (2007). El escritor argentino y la tradición. En Discusión. Emecé. O.C.T.I: 316-324.

Boyer, A. (2009). Archipelia, lugar de la relación entre (Geo) estética y poética. Nómadas (31), 13-25.

Самвоim Romano, O. (2018). Escola de Espectadores de Buenos Aires: uma pesquisa participante sobre mediacao teatral no cenário portenho (tesis inédita de doctorado). Universidade Federal da Bahia, Brasil. 
Collot, M. (2015). En busca de una geografía literaria de los textos. En García, M., Punte, M.J. y Puppo, M.L. (Comps). Espacios, imágenes y vectores. Desafios actuales de las literaturas comparadas. Buenos Aires: Miño y Dávila Editores, 59-75. Trad. M.L. Puppo.

Conti, H. (1993). Mascaró, el cazador americano. Buenos Aires: Emecé. Crolla, A.C. (2012). Literatura, territorialidad y matrices culturales. En Montezanti, M.A., y Matelo, G. (Coords.), El resto es silencio. Ensayos sobre Literatura Comparada (pp. 91-103). Biblos.

De Sousa Santos, B. (2001). Nuestra América. Reinventando un paradigma subalterno de reconocimiento y redistribución. Chiapas (12). Dubatтi, J. (2011). Apuntes sobre la institucionalización de los estudios de Teatro Comparado en la Argentina. Boletín de Literatura Comparada (XXXVI), 103-120.

Dubatti, J. (2012). Cien años de teatro argentino. Desde 1910 a nuestros días. Biblos-Fundación OSDE.

Dubatti, J. (2014). Convivio y tecnovivio: entre infancia y babelismo. En Filosofia del Teatro III. El teatro de los muertos (pp. 123-136). Atuel. Dubatтi, J. (2016). Teatro-matriz, teatro liminal. Estudios de Filosofia del Teatro y Poética Comparada. Atuel.

Dubatti, J. (Coord.) (2017). Dossier Escuelas de Espectadores. Paso de Gato (70), 19-60.

Dubatтı, J. (2019a). Arte, teatro y universidad: filosofía de la praxis, pensamiento y ciencias. En Casarín, M. (Coord.), Universidad, producción del conocimiento e inclusión social: a 100 años de la Reforma (pp. 147-176). Universidad Nacional de Córdoba, Facultad de Ciencias Sociales, Centro de Estudios Avanzados.

Dubatti, J. (2019b). Teatro Comparado y territorialidad. Hacia una nueva cartografía de los teatros argentinos. En Cámpora, M. y Puppo, M.L. (Coords.) Dinámicas del espacio. Reflexiones desde América Latina (pp. 99-112). Educa.

Dubatтi, J. (2019c). Espectadores: acción, liminalidad, historia. Conjunto (191), 11-21.

Dubatti, J. (Coord.) (2019d). Dossier Teoría, historia y gestión del espectador teatral. Paso de Gato (79), 19-58.

Foucault, M. (1980). Questions of Geography. En Gordon, C. (Ed.), Power/Knowledge: Selected Interviews and Other Writings, 1972-1977. Pantheon.

Foucault, M. (1986). Of Other Space. Diacritics (16).

García, M., Punte, M.J., y Puppo, M.L. (2015). Tres ejes para pensar las literaturas comparadas en el siglo XXI. En García, M., Punte, M.J., y Puppo, M.L. (eds.) Espacios, imágenes y vectores. Desafios actuales de las literaturas comparadas (13-24). Miño y Dávila Editores.

García Canclini, N. (1995). De las identidades en una época postnacionalista. Cuadernos de Marcha (101), 17-21.

García Lorca, F. (2008). En honor de Lola Membrives. En Obra completa VI. Prosa, 1, edic. M. García-Posada. (pp. 416-420). Akal. Garrote, A. (2019). Pundonor. Ediciones Hasta Trilce.

Gómez, C., y HADAD, M.G. (2007). Territorio e identidad. Reflexiones 
sobre la construcción de territorialidad en los movimientos sociales latinoamericanos. En IV Jornadas de Jóvenes Investigadores. Universidad de Buenos Aires, Facultad de Ciencias Sociales, Instituto de Investigaciones Gino Germani. https://www.aacademica.org/000-024/152

Groch, A. (2017). Semblanzas de apertura: sobre una experiencia de espectadores en ámbitos de encierro. Paso de Gato (70), 37-38.

Guattari, F. y Rolnik, S. (2006). Micropolítica. Cartografías del deseo. Tinta Limón Ediciones.

Guillén, C. (1998). Múltiples moradas. Ensayo de Literatura Comparada. Tusquets.

Haesbaert, R. (2004). O Mito da Desterritorializaçao. Do «fin dos territorios» à multiterritorialidade. Bertrand.

Hiernaux, D. y Lindón, A. (Dirs.) (2006). Tratado de Geografía Humana. Anthropos y Universidad Autónoma Metropolitana.

Kartun, M. (2014). Terrenal. Pequeño misterio ácrata. Apéndice crítico por J. Dubatti. Atuel.

Lefebvre, H. (1991). The Production of Space. Blackwell.

Mandoki, K. (2006). Prácticas estéticas e identidades sociales. Prosaica dos. Siglo XXI Editores.

PaAsi, A. (2003). Territory. En Agnew, J., Mitchell, K. and Toal, G. (Eds.). A Companion to Political Geography (pp. 109-122). Blackwell Publishing, Blackwell Reference Online.

Rojas, R. (2004). El país de la selva. Taurus.

Segato, R.L. (2002). Identidades políticas y alteridades históricas. Nueva Sociedad (178), 104-125.

Tally JR., R.T. (1996). Jameson's Project of Cognitive Mapping: A Critical Engagement. En Paulston, R. (Ed.) Social Cartography: Mapping Ways of Seeing Social and Educational Change (pp. 399-416). Garland.

Tally JR., R.T. (2015). Este espacio que nos carcome y nos desgarra. Foucault, la cartografía y la geocrítica. En García, M., Punte, M.J., y Puppo, M.L. (Comps). Espacios, imágenes y vectores. Desafios actuales de las literaturas comparadas [Trad. M. García] (pp. 77-93). Miño y Dávila Editores.

Vidal De La Blache, P. (1922). Principes de Géographie Humaine. Collin.

\section{Entrevista inédita}

JeLín, L. (2018) Entrevista en la Escuela de Espectadores de Buenos Aires.

\section{Video}

ZIFF, T. (2011). La maleta mexicana. Disponible en Youtube.

\section{Dubatti, Jorge}

«Teatro Comparado, territorialidad y espectadores: multiplicidades intraterritoriales». El hilo de la fábula. Revista anual del Centro de Estudios Comparados (20), 29-43. 